\title{
NOTE
}

\section{A further examination of two new taxonomic distinctness measures}

\author{
P. J. Somerfield ${ }^{1, *}$, F. Olsgard ${ }^{2}$, M. R. Carr $^{1}$ \\ 'Plymouth Marine Laboratory, Prospect Place, West Hoe, Plymouth PL1 3DH, United Kingdom \\ ${ }^{2}$ Section of Marine Zoology and Marine Chemistry, Department of Biology, University of Oslo, PO Box 1064, N-0316 Oslo, Norway
}

\begin{abstract}
In a previous note, Warwick \& Clarke (1995; Mar Ecol Prog Ser 129:301-305) used 2 indices, $\Delta$ and $\Delta^{\prime}$, to demonstrate a continuous decrease in taxonomic distinctness of marine macrofaunal assemblages along a gradient of increasing environmental contamination, in a situation where species diversity remained constant, in the vicinity of 1 oilfield in the Norwegian sector of the North Sea. These indices are tested here using species abundance data from 3 other oilfields in the Norwegian sector, each sampled on 3 different occasions. No consistent pattern of decreasing taxonomic distinctness with increasing environmental contamination is evident
\end{abstract}

KEY WORDS; Taxonomic distinctness Macrobenthos . Norway Offshore - Oilfields - Biodiversity

A recent paper (Warwick \& Clarke 1995) describes a pair of univariate 'biodiversity' measures, termed taxonomic diversity, $\Delta$, and taxonomic distinctness, $\Delta^{\circ}$. These use information derived from the hierachical taxonomic tree (e.g. a Linnean classification) upon which species identities are based. $\Delta$ is defined as the average (weighted) path length between every pair of individual organisms, with individuals in the same genus being closer than individuals in the same family, and so on. $\Delta^{*}$ is defined as the average (weighted) path length between every pair of individuals ignoring the paths between individuals of the same species.

These measures were formulated to take into account 2 main groups of observations. Firstly, it appears that in grossly perturbed situations species diversity is generally low but the dominant taxa are often those which also tend to have sympatric sibling species. For example, in areas impacted by gross organic enrichment the dominant species include polychaetes in the Capitella capitata complex of species and the genus Ophryotrocha, harpacticoid copepods of the genus Tisbe and nematodes of the family Oncholaimidae, all of which groups contain many closely related species. Secondly, in many studies of changes in community

\footnotetext{
•E-mail: p.somerfield@pml.ac.uk
}

composition in relation to perturbation, particularly those which examine intermediate levels of disturbance, standard univariate measures of community structure which do not use information about the identity of species, such as the Shannon-Wiener diversity measure $\left(H^{\prime}\right)$ or Margalef's $d$, often appear to be homeostatic, in that a response generally has to be very marked before differences between stations become statistically significant, and do not therefore reveal intermediate responses. Conversely, multivariate analyses which utilise information about the identity of species are often extremely sensitive (e.g. Gray et al. 1990, Warwick \& Clarke 1991, Dawson Shepherd et al. 1992, Olsgard \& Gray 1995). Thus the new univariate measures were designed to incorporate an element of multivariate information, in the form of taxonomic distinctness, and these were then tested on species abundance data from a survey conducted in 1987 around the Ekofisk oilfield in the Norwegian sector of the North Sea (Gray et al. 1990). $\Delta^{*}$ was found to be the most sensitive univariate measure of community structure for these data. In fact, due to a minor technical error, Warwick \& Clarke's (1995) Fig. 3 has the wrong $y$-axis scaling for the $\Delta$ and $\Delta^{*}$ plots. This figure is replotted here (Fig. 1) and, as reported by Warwick \& Clarke (1995), both measures increase linearly with distance from the centre of the field, unlike $H^{\prime}$, which is depressed within a few $100 \mathrm{~m}$ of the centre of the field only. Although not mentioned in Warwick \& Clarke's paper, there is also a significant $(p=0.024)$ decrease in the numbers of species (S) with distance from the centre of the field (Table 1). The Ekofisk field is, however, only one of many in the North Sea. Olsgard \& Gray (1995) presented analyses of benthic communities around several other fields in the Norwegian sector. The present study utilises some of these data to ascertain whether the pattern demonstrated by Warwick \& Clarke (1995) is repeated around other fields.

Methods and results. Macrofaunal species abundance data from surveys around 3 offshore oilfields in the Norwegian sector of the North Sea (Fig. 2) are used 


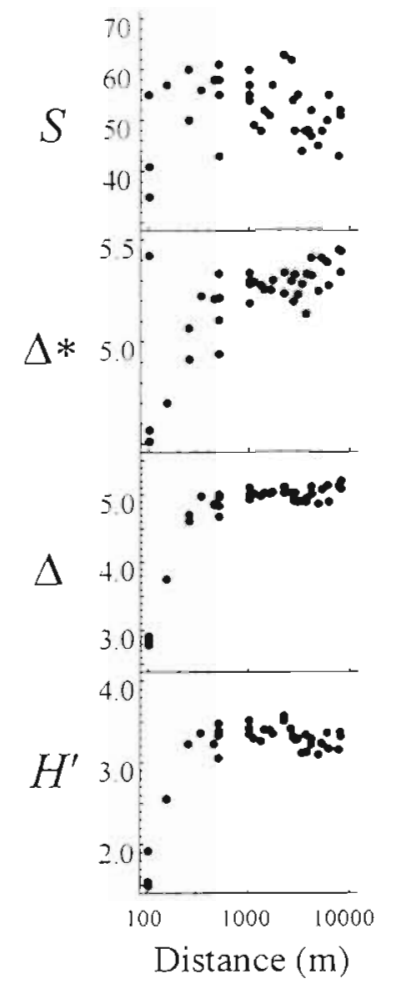

Fig. 1. No. of species (S), taxonomic distunctness $\left(\Delta^{*}\right)$, taxonomic diversity $(\Delta)$. and Shannon-Wiener diversity $\left(H^{\prime}\right)$ plotted against distance (log scale) from the centre of the Ekofisk field in 1987

in this study. The fields are (from south to north) Valhall, sampled in 1985, 1988 and 1991, Gyda, sampled in 1987, 1990 and 1993, and Veslefrikk, sampled in the same years as Gyda. Surveys at the Valhall field commenced a few years after the initiation of drilling activity, while at the other 2 fields the first surveys preceded the initiation of major drilling activity. In each survey samples were taken at various distances from the centre of the field along 4 transects arranged in a cross pattern. Detailed analyses of these data are to be found in Olsgard \& Gray (1995).

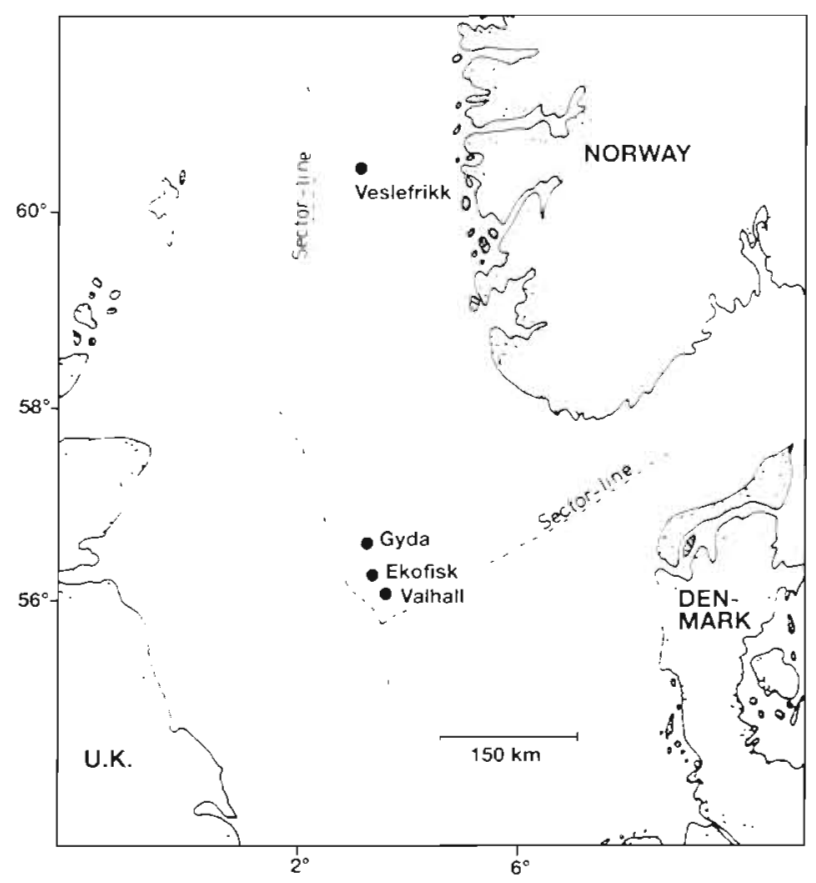

Fig. 2. Locations of the Ekofisk, Valhall, Gyda and Veslefrikk oilfields in the North Sea

Following the methods given in Warwick \& Clarke (1995) species aggregation files were constructed using a standard classification (Howson 1987) and the taxonomic levels of species, genus, family, order, class and phylum, and these were used to calculate $\Delta$ and $\Delta^{*}$ using weightings of 1 to 6 for the increasing taxonomic levels. As noted by Warwick \& Clarke, the taxonomic hierarchy is somewhat arbitrary, as is the allocation of the linear scale of weightings 1 to 6 to the taxonomic levels, but as the aim of the present study is to evaluate the measures as described rather than to develop them further, we have formulated them in exactly the same

Table 1. Slope and significance ( $\mathrm{p}$, from $2 \mathrm{df}$, values of $\mathrm{p}<0.05$ in bold) of ordinary least squares regressions of the 4 indices against $\log$ of distance from the field centre for Ekofisk (in 1987) and each of the other 9 surveys. Samples within $750 \mathrm{~m}$ of the field centres ( $150 \mathrm{~m}$ for Ekofisk) were omitted, and $\mathrm{n}=$ number of remaining cases

\begin{tabular}{|c|c|c|c|c|c|c|c|c|c|c|}
\hline Field & Year & n & $S$ & $p$ & $\Delta^{*}$ & $p$ & $\Delta$ & $\mathrm{p}$ & $H^{\prime}$ & $\mathrm{p}$ \\
\hline Ekofisk & 1987 & 35 & -2.103 & 0.024 & 0.080 & $<0.001$ & 0.074 & $<0.001$ & -0.017 & 0.427 \\
\hline Valhall & 1985 & 9 & 2.504 & 0.484 & 0.386 & 0.033 & 0.295 & 0.601 & 0.130 & 0.726 \\
\hline Valhall & 1988 & 16 & 7.368 & 0.001 & 0.223 & 0.001 & 0.334 & $<0.001$ & 0.266 & $<0.001$ \\
\hline Valhall & 1991 & 21 & 8.614 & $<0.001$ & 0.100 & 0.012 & 1.066 & $<0.001$ & 0.724 & $<0.001$ \\
\hline Gyda & 1987 & 14 & 1.526 & 0.440 & -0.007 & 0.839 & 0.043 & 0.244 & 0.080 & 0.119 \\
\hline Gyda & 1.990 & 13 & 10.488 & 0.003 & -0.049 & 0.096 & -0.007 & 0.877 & 0.126 & 0.044 \\
\hline Gyda & 1993 & 16 & 4.939 & 0.005 & -0.024 & 0.450 & -0.029 & 0.471 & 0.007 & 0.898 \\
\hline Veslefrikk & 1987 & 9 & 4.931 & 0.078 & 0.030 & 0.071 & 0.046 & 0.460 & 0.073 & 0.404 \\
\hline Veslefrikk & 1990 & 15 & -3.212 & 0.310 & 0.059 & 0.548 & 0.150 & 0.372 & 0.187 & 0.200 \\
\hline Veslefrikk & 1993 & 13 & -10.969 & 0.087 & 0.083 & 0.272 & 0.284 & 0.194 & 0.243 & 0.282 \\
\hline
\end{tabular}



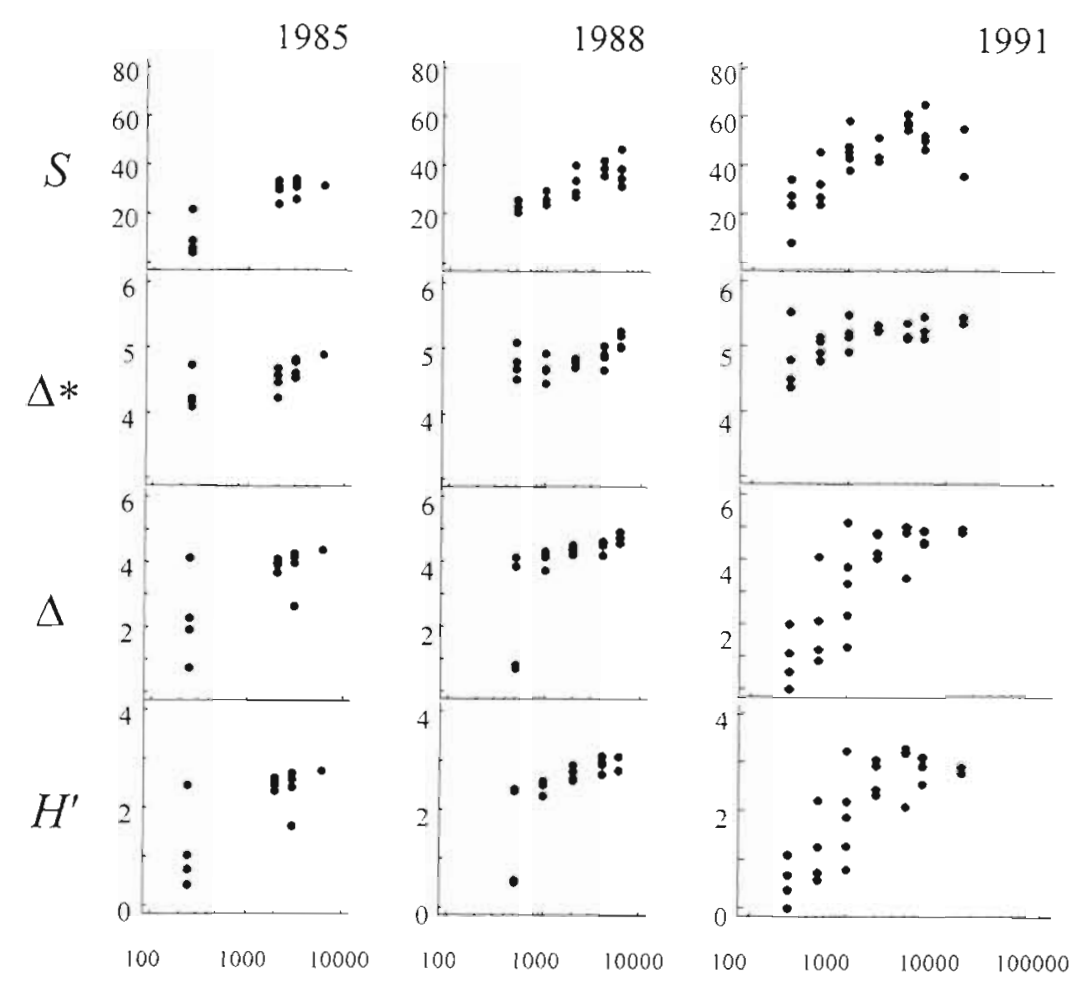

Distance $(\mathrm{m})$

Fig. 3. $S, \Delta^{*}, \Delta$ and $H^{\prime}$ plotted against distance (log scale) from the centre of the Valhall field in 1985, 1988 and 1991

manner. Patterns in these measures are compared with patterns in $S$ and $H^{\prime}$ calculated using natural logarithms.

ificant increase with distance from the centre of the Valhall field in the 1985 survey (Fig. 3, Table 1), the patterns in univariate indices from the surveys in 1988 and 1991 are all very similar, all showing a significant increase with distance from the centre of activity (Fig. 3, Table 1).

Patterns in univariate measures derived from surveys around the Gyda field (Fig 4, Table 1) in 1987 do not show any clear patterns, as might be expected as no clear contamination gradient was established at the time. By 1990, however, a gradient was established (Olsgard \& Gray 1995) and this is reflected in the univariate measures, $S$ and $H^{\prime}$, which increase significantly, albeit marginally so, with distance from the centre of drilling activity, whereas the trends in $\Delta^{*}$ and $\Delta$ are not significant. By 1993 , however, the increasing trend in $H^{\prime}$ has disappeared, and only $S$ increases significantly with distance from the field centre (Table 1).

Ekofisk, Valhall and Gyda are all located in the southern part of the Norwegian sector, in areas of homogeneous sediment where unper- turbed benthic communities might also be expected to be relatively homogeneous. Veslefrikk, on the other hand, is located to the north, in an area with relatively heterogeneous benthic environmental conditions. There are no clear patterns (Fig 5) or significant trends (Table 1) in univariate measures from this field in any of the 3 surveys.

Discussion. Calculated according to the formulae in Warwick \& Clarke (1995), using the same taxonomic hierarchy (Howson 1987) and weightings ( 1 to 6 for species to phyla), neither $\Delta^{*}$ nor $\Delta$ reveal a steady increase in taxonomic distinctness with increasing distance from the centre of drilling activity in any of the surveys examined, with the exception of those from Valhall, where there are strong patterns in $S$ and $H^{\prime}$ as well in all but the first survey. This is in contrast to the findings of the earlier study, which were based on a survey from the Ekofisk field in 1987 (Gray et al. 1990). Several factors could have a bearing on these results.
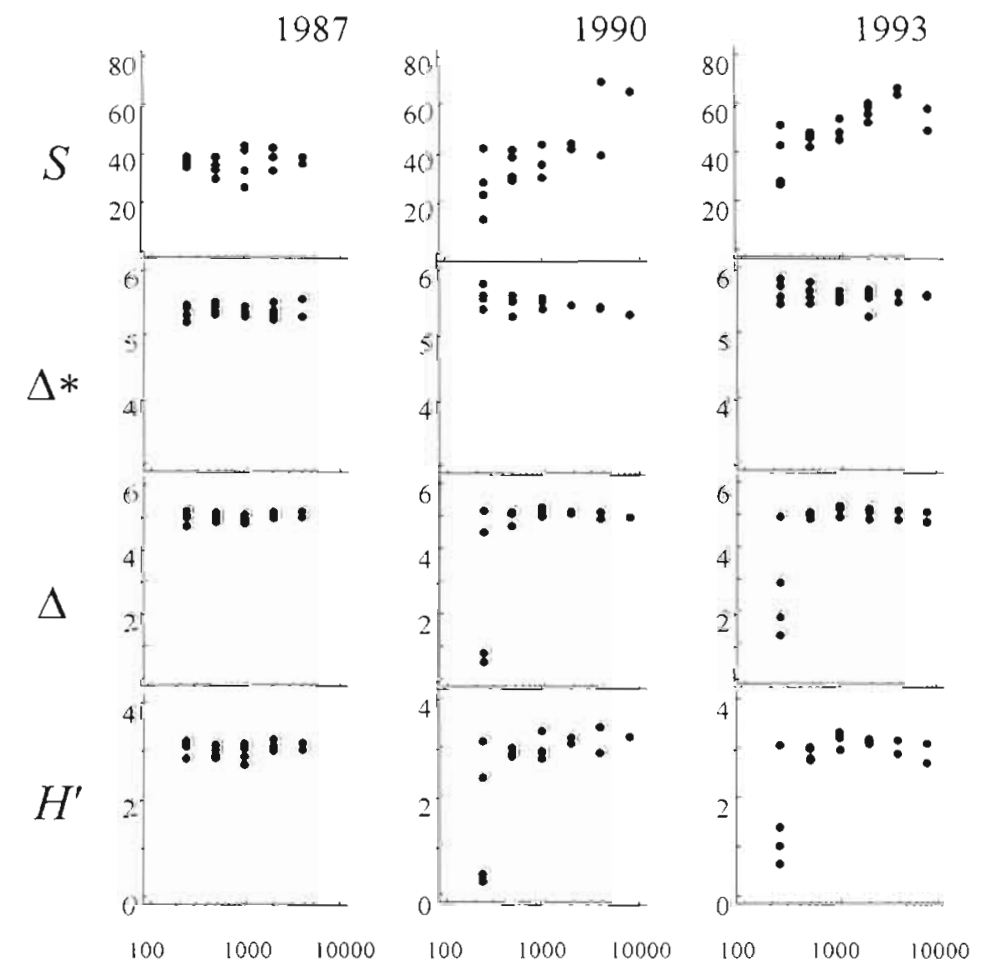

Distance $(\mathrm{m})$

Fig. 4. $S, \Delta^{\bullet}, \Delta$ and $H^{\prime}$ plotted against distance (log scale) from the centre of the Gyda field in 1987, 1990 and 1993 


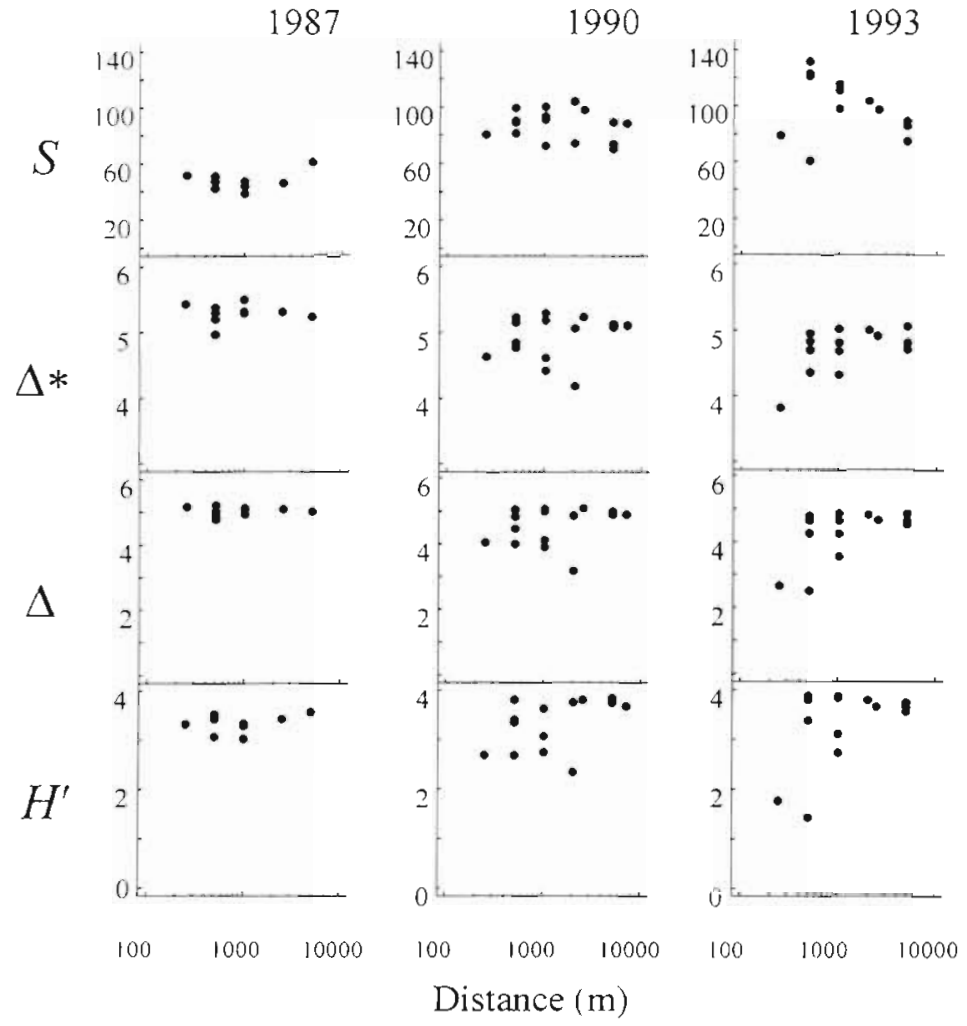

Fig. 5. $S, \Delta^{\circ}, \Delta$ and $H^{\prime}$ plotted against distance (log scale) from the centre of the Veslefrikk field in 1987, 1990 and 1993 decrease in $\Delta^{*}$ without a corresponding decrease in $H^{\prime}$ ', such as at Ekofisk (Fig 1). It is likely that gradients in taxonomic distinctness only develop slowly by this second mechanism, as it would clearly require a timescale of a number of generations for a community containing groups of closely related species to develop.

Although no consistent pattern of decreasing taxonomic distinctness with increasing environmental contamination is evident in the survey data examined here, this should not be taken to mean that the measures proposed by Warwick \& Clarke (1995) have no value. Although $\Delta$ is closely related to $H^{\prime}$ when a gradient in taxonomic distinctness is absent, it is relatively insensitive to variation in the numbers of individuals within samples. There is increasing recognition of the relevance of information about the interrelationships between species in the context of biodiversity (Harper \& Hawksworth 1994) and $\Delta^{*}$, which is also sample-size independant, conveys information about this aspect of community structure which is completely ignored in the calculation of standard indices. It also has theoretical possibilities which are worthy of further examination.
As stated in Warwick \& Clarke (1995), $\Delta$ is empirically related to $H^{\prime}$, with an added component of taxonomic distinctness. In the surveys examined in this study, the patterns in $\Delta^{*}$ do not suggest that there is a consistent decrease in taxonomic distinctness with increasing environmental contamination. In a situation where $\Delta^{*}$ remains constant, it is to be expected that $\Delta$ will track $H^{\prime}$ closely, and the concordance of the graphs of $H^{\prime}$ and $\Delta$ in the absence of strong gradients in $\Delta^{*}$ (Figs. $4 \& 5$ ) confirms this. Exploration in the Ekofisk field began in the late 1960s (Gray et al. 1990), and so the survey on which Warwick \& Clarke (1995) based their study was conducted after approximately $20 \mathrm{yr}$ of activity. The surveys on which the present study is based were conducted relatively early in the lives of the fields. There are 2 possible mechanisms for the development of gradients in taxonomic distinctness. If a disturbance acts to remove species from an assemblage selectively, from particular higher taxa for example, then one might expect a situation where both $\Delta^{*}$ and $H^{\prime}$ decrease in response to that stress. Such a mechanism may underlie the patterns observed at the Valhall field (Fig. 3). The second mechanism is the replacement of less closely related species by more closely related species in areas of increased stress. Such a mechanism would be expected to lead to a
Acknowledgements. This work was done within the Marine Biodıversity project of the Plymouth Manne Laboratory, and is a contribution to Project no. AE1113, funded by the UK Ministry of Agriculture, Fisheries and Food. This study was also funded in part by grants to F.O. from the Norwegian Research Council and NATO. We thank R. M. Warwick and K. R. Clarke for their assistance with the manuscript.

\section{LITERATURE CITED}

Dawson Shepherd AR, Warwick RM, Clarke KR, Brown BE (1992) An analysis of fish community responses to coral mining in the Maldives. Environ Biol Fish 33:367-380

Gray JS, Clarke KR, Warwick RM, Hobbs G (1990) Detection of initial effects of pollution on marine benthos: an example from the Ekofisk and Eldfisk oilfields, North Sea. Mar Ecol Prog Ser 66:285-299

Harper JL, Hawksworth DL (1994) Biodiversity: measurement and estımation. Preface. Philos Trans R Soc Lond B Biol Sci $345: 45-58$

Howson CM (ed) (1987) Species directory to British marine fauna and flora. Marine Conservation Society, Ross-on-Wye

Olsgard F, Gray JS (1995) A comprehensive analysis of the effects of offshore oil and gas exploration and production on the benthic communities of the Norwegian continental shelf. Mar Ecol Prog Ser 122:277-306

Warwick RM. Clarke KR (1991) A comparison of some methods for analysing changes in benthic community structure. J Mar Biol Assoc UK 71:225-244

Warwick RM, Clarke KR (1995) New 'biodiversity' measures reveal a decrease in taxonomic distinctness with increasing stress. Mar Ecol Prog Ser 129:301-305 


\section{ERRATUM}

\section{A further examination of two new taxonomic distinctness measures}

\section{P. J. Somerfield, F. Olsgard, M. R. Carr}

Mar Ecol Prog Ser 154: 303-306, 1997

- On page 305 the first line of the first complete paragraph was missing. The corrected paragraph is given in full here:

Although $\Delta^{*}$ is the only index to show a significant increase with distance from the centre of the Valhall field in the 1985 survey (Fig. 3, Table 1), the patterns in univariate indices from the surveys in 1988 and 1991 are all very similar, all showing a significant increase with distance from the centre of activity (Fig. 3, Table 1). 